\section{Emmetropization, visual acuity, and strabismus outcomes among hyperopic infants followed with partial hyperopic corrections given in accordance with dynamic retinoscopy}

D Somer, E Karabulut, FG Cinar, UE Altiparmak and N Unlu

\begin{abstract}
Object To record emmetropization, visual acuity, and strabismus outcomes among hyperopic infants followed with partial hyperopic corrections given in accordance with dynamic retinoscopy (DR).

Methods Infants (3.5-12 months of age) with $\geq 5 \mathrm{D}$ hyperopia were followed without glasses or partial hyperopic corrections prescribed according to their near dynamic accommodative abilities determined by DR responses at the initial visit and follow-ups. Refraction and binocular accommodative ability assessments were made at 3-month intervals up to the age of 1 and at 6-month intervals afterwards for a mean $35.4 \pm 2.1$ months; main outcome measures being the development of esotropia, emmetropization rate, and visual acuity level after emmetropization period.

Results Among 211, 146 were normal accommodators initially (Group 1). These infants were followed without treatment and none presented with strabismus. Sixty-five infants were hypo-accommodators (Group 2) and received minimum DR-based corrections. Of the 65 infants $31(48 \%)$ developed strabismus (Group 2B). The remaining 34 constituted Group 2A. Each of the three groups showed an overall reduction of hyperopia by $0.37 \pm 0.25$ days per year, $0.50 \pm 0.28$ days per year, and $0.60 \pm 0.20$ days per year, respectively. Visual acuity assessments among Groups 1 and $2 \mathrm{~A}$
\end{abstract}

revealed normal values (0.2-0.0 LogMAR); among Group 2B 19\% were within normal range.

Conclusions Binocular accommodative behavior at the initial visit seems to be one of the indicators for pointing out infants at risk of developing strabismus and amblyopia. Prescription of DR-based corrections to hyperopic orthotropic infants does not impede emmetropization and result in normal visual acuities after emmetropization period.

Eye (2014) 28, 1165-1173; doi:10.1038/eye.2014.161; published online 18 July 2014

\section{Introduction}

Pediatric ophthalmology professionals face a dilemma in the management of hyperopia in orthotropic infants. Early prescription of glasses has been suggested as a way of setting preventive measures for the early development of strabismus and amblyopia. Also, use of a refractive correction in early infancy seems to yield a marked improvement in distance acuity and the accuracy of accommodationimportant visual benefits in addition to those relevant to amblyopia risk. ${ }^{1-5}$ However, if a decision on a prescription is made, it also introduces the tendency to place undue weight on with the wearing of spectacles in the face of deferring the development of emmetropization. ${ }^{6-17}$ This concern raises a question that is yet to be
Department of Pediatric Ophthalmology and Strabismus, S.B. Ankara Education and Research Hospital, Ankara, Turkey

Correspondence: D Somer, Department of Pediatric Ophthalmology and Strabismus, Ankara Education and Research Hospital, 06340 Ankara, Turkey.

E-mail: dsomer@mc.metu. edu.tr

Received: 7 September 2013

Accepted in revised form: 30 May 2014

Published online: 18 July 2014

This study has been presented as an oral presentation at the 37th Annual Meeting of the American Association for Pediatric Ophthalmology and Strabismus. 
answered: do hyperopic children really need the provision of full plus refractive error correction to meet these objectives?

Dynamic retinoscopy (DR) can perhaps guide the decision. Binocular accommodative ability assessment with DR gives important information about the binocular status of an infant. ${ }^{18-21}$ If accommodation is full, there is evidence that the baby is able to focus images onto the retina while maintaining binocular vision at near. DR assessment can in theory determine if a child is not esotropic simply because they are not accommodating, or if they are fully accommodating but have a good fusional reserve or some mechanism to overcome the eso drive. It can also tell, in theory, just how much plus infants need to be in focus for near vision, and if that is less than full plus, prescribing that amount might allow for better emmetropization. This amount which allows for full accommodation might in theory also increase the tendency toward emmetropization, as there is existing evidence that better accommodation is associated with better emmetropization. ${ }^{2,3,22-25}$

Dynamic accommodative ability appears to be present at 2 months of age and improves up to the age of 3 to 4 months. ${ }^{18,22,25}$ During the first year, the majority of the refractive change takes place between 3 and 12 months of age as there is little change between birth and 3 months. $2,12,21-25$ An accurate accommodative response, therefore, appears to be in place at the time when the emmetropization process begins.

We followed hyperopic infants without treatment or with partial hyperopic corrections based on DR, according to their near dynamic accommodative abilities determined by DR responses at the initial visit and follow-ups. The purpose of the study was, first, to see if partial-spectacle corrections given in accordance with DR had any beneficial effect in reducing strabismus and amblyopia without interfering with the development trend toward emmetropia; second, whether DR appeared to be a very useful diagnostic tool for deciding whether to provide an optical correction for an infant with hyperopia; and third, whether DR could be used to determine the amount of partial corrections. Some researchers conducted trials of correcting infantile hyperopic refractive errors with partialspectacle corrections, but as far as we are concerned, a decisive and predictive approach to establish the amount of hypo-correction to overcome the abovementioned concerns has not been defined. $1,5,12$

\section{Materials and methods}

Initial data for this prospective study were obtained from dynamic retinoscopic and cycloplegic refractive assessments made as part of the ophthalmic examinations of infants under 1 year of age (3.5-12 months) who presented to our clinic for reasons unrelated to refractive error. Infants identified with $\geq 5 \mathrm{D}$ hyperopia (cycloplegic retinoscopy figure) in at least one meridian of either eye without anisometropia of $1.50 \mathrm{D}$ or greater of sphere or cylinder were recruited for the study. Infants with a history of preterm birth ( $<36$ weeks' gestational age at birth), with diagnosed developmental delay, neurological, syndromic, or other coexisting disease were not recruited. A family history of strabismus was also an exclusion criterion. The families were told that their child was identified as being at risk for strabismus and amblyopia and was included in this long-term study because of the possibility of preventing these issues. Approval of the study was obtained from the institutional review board and informed consent was gained from all participating families conforming to all local laws and principles of the Declaration of Helsinki.

Binocular accommodative ability was assessed by DR on all infants at the time of initiation of the study and was repeated at each follow-up attendance prior to refraction measurement. Each infant was encouraged to fixate binocularly on a detailed fixation target (squeaky toys for small babies) placed in the plane of the retinoscope, with the retinoscope and target held at $33 \mathrm{~cm}$. When a prior decision for the underaccommodating infants who were to receive glasses had been made, DR was performed with the current spectacle correction in place. We have concentrated on changes in the spherical refraction, because eyes of infants naturally focus on the least hyperopic meridian. ${ }^{18,24,26}$ For this reason, in most cases, the meridian of least hyperopia was used and the assessments were made in that meridian on follow-up visits. If accommodation was accurate, then the reflex would be neutral (ie, $\mathrm{N} / \mathrm{N}$ response). The results of DR were described as normal only if it was 'rapid, complete, and steady'. If the child was underaccommodating in both eyes (ie, there was a lag of accommodation) then a 'with' movement was seen $(\mathrm{H} / \mathrm{H}$ response), and the examiner introduced a lens estimated to neutralize the perceived motion. The examiner continued to introduce plus lenses (in $0.25 \mathrm{D}$ steps) in front of one eye and then the other until the lowest power lens that resulted in neutrality in the two corresponding meridians of the two eyes was determined (monocular estimated method ${ }^{17,18,20}$ ).

Infants were followed without prescriptions or with partial hyperopic corrections in accordance with initial DR responses. At the initiation of the study, infants that had neutral DR responses in either or both of the corresponding meridians (the term corresponding meridians refers to vertically or horizontally corresponding meridians in two eyes) in both eyes were 
designated as 'normal accommodators' and were followed without spectacle corrections. In other words, the corresponding fixating meridians of these infants would have neutral responses; the corresponding nonfixating meridians would have either neutral or 'with' responses. Infants that had 'with' DR responses (ie, binocular accommodative insufficiency) in both of the corresponding meridians (ie, fixating and non-fixating meridians) initially were designated as hypoaccommodators and were prescribed minimum partial hyperopic corrections that neutralized the 'with' motion in the fixating meridians of both eyes and allowed for full binocular accommodative responses. A refractive error of astigmatism $\geq 0.50 \mathrm{D}$ (cycloplegic refraction) was also included in the prescriptions. These minimum corrections to help maintain full binocular accommodative responses at near were prescribed to be worn full time. Refraction measurements were performed after cycloplegia with $1 \%$ cyclopentolate, which was instilled twice (at 40 and $30 \mathrm{~min}$ ) before retinoscopy and were verified using a hand-held autorefractometer (Retinomax, Nikon Corporation, Tokyo, Japan).

Among both normal and hypo-accommodators, orthoptic examinations, cycloplegic refractions, and binocular accommodative ability assessments with DR were conducted at 3-month intervals up to the age of 1 year and at 6-month intervals afterwards. The participating families were also asked to attend promptly if they ever noticed a strabismic eye. If strabismus was detected at any age, follow-up visits afterwards were conducted at 3-month intervals.

Visual acuities were assessed with Lea symbols (GoodLite Line Distance Chart, Good-Lite Company, Elgin, IL, USA) when verbal communication became possible. ${ }^{27-29}$ Visual acuity was defined as the line at which four out of the five symbols were correctly identified. During visual acuity assessment, eyes were designated as fixating or non-fixating according to their last cycloplegic refractive figure or vision. If these were equal, they were randomly designated.

All measurements were taken separately by two ophthalmologists (DS and EK) and compared.

Among the 264 infants fulfilling the inclusion criteria, 53 were excluded, as compliance was judged to be unsatisfactory due to reasons such as more than one appointment missed, inconsistent wearing of glasses, and insufficient maturity to complete visual acuity testing. For the purpose of this study, children were allocated into groups according to their accommodative responses and the development of strabismus. Among the 211 assigned, 146 had neutral DR responses in either or both of the corresponding meridians at the time of initiation of the study. These patients were followed without spectacle corrections and constituted Group 1 (normal accommodators). The remaining 65 infants had 'with' DR responses (ie, binocular accommodative insufficiency) in both of the corresponding meridians initially. These patients were prescribed minimum partial hyperopic corrections that neutralized the 'with' motion in the fixating meridians of both eyes and allowed for full binocular accommodative responses (Group 2; hypoaccommodators).

The mean follow-up was $35.4 \pm 2.1$ (range, 31-39 months) months after first referral. If an infant in either group developed strabismus, the time of detection was defined as the date when it was diagnosed by one of the ophthalmologists. At the time of detection, partial corrections were changed with prescriptions incorporating full refraction, which was based on the cycloplegic retinoscopy refraction performed at $50-\mathrm{cm}$ (2D) working distance.

The refractive and dynamic retinoscopic data for each group were examined and statistically compared, the main outcome measures being the loss of hyperopia (which reflects emmetropization), development of esotropia, and the level of visual acuity after the emmetropization period.

SPSS for Windows 15.0 (SPSS Inc, Chicago, IL, USA) was used as data analysis software. The distribution of continuous variables for normality was tested with the Shapiro-Wilk test, and data were presented as mean \pm standard deviation (SD). Categorical variables were reported as percentages. Between groups, ANOVA was used for testing differences in means while Kruskal-Wallis was used for testing differences in distributions (medians). If the $P$-value obtained from these tests was statistically significant, post-hoc Bonferroni or non-parametric multiple-comparison tests were used to determine which group differed from the others. To analyze the difference of repeated measures in groups, $t$-test was used. A value of $P<0.05$ was considered statistically significant.

\section{Results}

Binocular accommodative ability was not always found to be a function of the level of hyperopia. Some infants accommodated efficiently with high-diopter powers (eg, $7 \mathrm{D})$ while others did not, with diopter powers as low as 3.25 D (Table 1).

During follow-up, strabismus development was not demonstrated among any with initial neutral DR responses in the fixating meridians (ie, those who did not wear glasses-the 146 patients in Group 1). Among the remaining 65 infants with initial binocular accommodative insufficiency (Group 2; hypoaccommodators) who were followed with partial 
Table 1 Hyperopic refractive data according to initial dynamic retinoscopy responses ${ }^{\mathrm{a}}$

$H / H(\mathrm{n}=65) \quad N / N(\mathrm{n}=146)$

Initial hyperopia (D) (fe) $6.19 \pm 1.86(3.25-11) 3.90 \pm 0.79$ (3-7) Initial hyperopia (D) (nfe) $6.75 \pm 1.93$ (3.25-12) $4.33 \pm 0.74$ (3-7)

Abbreviations: $\mathrm{D}$, diopters (cycloplegic refraction-2.0 D); fe; fixating eye; $\mathrm{n}$, number of cases; nfe; non-fixating eye.

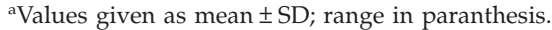

hyperopic corrections, $31(47.7 \%)$ developed a convergent strabismus at a mean age of $29.3 \pm 7.3$ (range 18-42) months (Group 2B; esotropic hypoaccommodators). The remaining 34 babies without strabismus were allocated as Group 2A (ortho hypoaccommodators). All children recorded as having strabismus had accommodative esotropia.

All infants in Group 1 (normal accommodators) and all infants in Group 2A (ortho hypo-accommodators) had 0.63-1.0 decimal (0.2-0.0 LogMAR) visual acuities (normal values for this age interval) in both eyes at the termination of the study. All children with strabismus development (Group 2B) demonstrated lower visual acuities; both eyes of only $19 \%$ were within the range of the normal vision (Figure 1). Vision in the fixating and non-fixating eyes of these strabismic children were within less than two lines of interocular difference in visual acuity.

In an attempt to determine whether accommodative responses differed between Groups 2A and 2B before the onset of esotropia and/or altered after the development of strabismus, refractive data in the fixating hyperopic meridians were compared with prescriptions given in accordance with DR. Before the onset of esotropia, hyperopic prescriptions were mean $1.6 \pm 0.4$ and $1.62 \pm 0.5 \mathrm{D}$ (mean $\pm \mathrm{SD}$ ) lower than initial refractions among Groups $2 \mathrm{~A}$ (ortho hypo-accommodators) and 2B (esotropic hypo-accommodators), respectively, (Tables 2a and b) with no significant difference in accommodative responses $(P>0.05)$ among groups. After the onset of esotropia, partial corrections were changed with prescriptions incorporating full cycloplegic refraction (ie, there was no difference between refractions and refractive corrections after the onset of strabismus).

An assessment of whether accommodative responses had altered after the development of strabismus was attempted, and DR was performed over the last prescription (which was the final refractive figure) among Group 2B. The least hyperopic correction that resulted in neutral responses on the two corresponding meridians of the two eyes was established and compared with differences of the period before the establishment of strabismus. After the onset of esotropia, accommodative responses among Group 2B were significantly diminished compared with Group 2A $(P=0.04)$ (Table $2 b)$. Also inside Group 2B, significant decreases in accommodative responses were established $(P=0.002$ for fixating eyes and $P<0.001$ for non-fixating eyes) (Table 2c). We attempted to investigate whether initial anisometropia increased with our approach. Among those in Group 2B, at the onset of the study, a mean of $0.70(0.31) \mathrm{D}$ initial refractive anisometropia was reduced to a mean of $0.54(0.43) \mathrm{D}$, with spectacles given according to DR (Table 3 ). By the time of detection of strabismus, the difference between refractive and spectacle anisometropia had increased, and spectacle anisometropia had reached a level of mean 0.86 (0.53) D. The differences between refractive and spectacle anisometropia among Groups $2 \mathrm{~A}$ and $2 \mathrm{~B}$ were not significant $(P=0.69)$. The higher mean spectacle anisometropia among Group 2B, which was still under $<1.0 \mathrm{D}$, was related to the higher amount of mean refractive anisometropia compared with those in Group 2A (0.60 (0.51) D and $0.83(0.57) \mathrm{D}$ among Groups 2A and $2 \mathrm{~B}$, respectively).

Each of the three groups showed significant reductions $(P<0.001)$ of the mean hyperopia in both eyes (Table $4 \mathrm{a})$. Over the period of the study, Groups 2A and 2B demonstrated greater decreases in hyperopia compared with Group 1 ( $P<0.001$ and $P=0.0046$ accordingly). There was no significant difference in emmetropization among Groups 2A and 2B. In Groups 1, 2A, and 2B, analysis comparing the emmetropization rates of the fixating and non-fixating eyes revealed no significant difference $(P>0.05)$ (Table $4 b)$.

Among Group 2, once the decision on a prescription was made at the initial visit, infants were constantly wearing glasses that changed the $\mathrm{H} / \mathrm{H}$ responses to $\mathrm{N} / \mathrm{N}$ responses (ie, none of the infants presented with $\mathrm{H} / \mathrm{H}$ DR responses throughout the study period). In assessing emmetropization, we therefore have not attempted to relate emmetropization to whether the infants did or did not have $\mathrm{H} / \mathrm{H}$ responses.

\section{Discussion}

DR appears to be a useful diagnostic tool for deciding whether to provide optical correction for an orthotropic infant with significant hyperopia. Infants with initial hypo-accommodative responses are candidates for esotropia and amblyopia and need prescriptions. Prescribing hyperopic correction according to the least amount needed to allow for near focusing, based on DR, does not impede emmetropization and also offers beneficial effects in reducing amblyopia. 
Perhaps the most interesting and useful result of our findings relates to the possible association between initial DR responses and the future development of strabismus. Hyperopic orthotropic infants with normal accommodation with DR never developed an esotropia, even without treatment. Also, only infants with $\mathrm{H} / \mathrm{H}$ responses at the first visit were future candidates for strabismus; nearly half of these patients $(47.7 \%)$ developed esotropia during followup. Our data show binocular accommodative behavior at the initial visit to be one of the indicators for pointing out infants' risk of developing strabismus and amblyopia.

It is not clear why some children with initial hypoaccommodation developed strabismus while the others

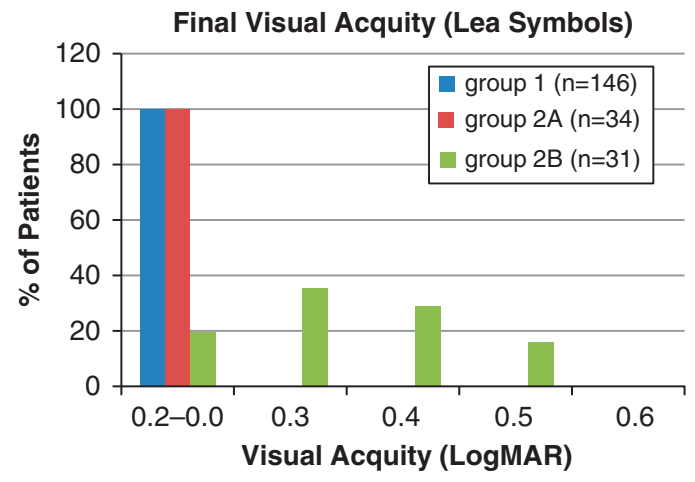

Figure 1 Final visual acuity. did not. At the time of detection of esotropia and afterwards, accommodative ability was reduced. This was demonstrated by performing DR over the full plus prescriptions and comparing these data with the period before. Issues regarding accommodation may be related in some way with the development of esotropia.

Strabismus development was unlikely to be the result of interocular rivalry as visual acuity differences between fixating and non-fixating eyes were within two lines. If these hyperopic children developed strabismus because blur-induced accommodation drove convergence, we asked ourselves first why DR-based prescriptions that had nullified the need for extra accommodation did not prevent them from the strabismus, and second, why preserving full binocular accommodation, evidence of both images falling onto the retina, did not prevent vision deprivation among cases with strabismus development.

At each visit, we cut the extra plus from the spherical original refractions according to binocular accommodative responses. This approach might raise concerns for increasing the amount of initial anisometropia (ie, refractive anisometropia detected at initial cyclo-refraction) (Professor BJ Kushner, personal communication). If differences of accommodative deficiencies between fixing eyes and their non-fixating fellows increased over time, prescribing corrections according to DR would result in significant increases in initial anisometropia and extra vision deprivation that would contribute to the development of strabismus.

Table 2a Initial and final mean refractive (spherical) corrections given in accordance with DR

\begin{tabular}{|c|c|c|c|}
\hline & Group $2 A(\mathrm{n}=34)$ & Group $2 B(\mathrm{n}=31)$ & $\begin{array}{c}\text { Group } 2 B(\mathrm{n}=31) D R \text { data } \\
\text { over last prescription }\end{array}$ \\
\hline Initial spherical prescription (D) (fe) & $3.30 \pm 0.98$ (range: $2.0-5.0$ ) & $5.99 \pm 1.45^{\mathrm{a}}$ (range: $3.0-9.0$ ) & \\
\hline Initial spherical prescription (D) (nfe) & $3.78 \pm 1.04$ (range: $2.0-6.0$ ) & $6.50 \pm 1.47^{\mathrm{a}}$ (range: $3-10.0$ ) & \\
\hline Final spherical prescription (D) (fe) & $1.80 \pm 0.80$ (range: $0.50-3.0)$ & $5.80 \pm 1.86^{\mathrm{b}}($ range: $3.50-10.0)$ & $4.65 \pm 1.89^{c}$ (range: $\left.2.0-9.0\right)$ \\
\hline Final spherical prescription (D) (nfe) & $2.42 \pm 0.87$ (range:1.0-4.50) & $6.50 \pm 1.70^{\mathrm{b}}$ (range: $\left.4.0-10.50\right)$ & $5.39 \pm 1.84^{\mathrm{c}}$ (range: $\left.3.0-9.5\right)$ \\
\hline
\end{tabular}

Table $2 \mathrm{~b}$ Accommodative response changes among ortho and esotropic hypo-accommodators

\begin{tabular}{|c|c|c|}
\hline & Group $2 A$ (ortho hypo-accommodators) & Group 2B (esotropic hypo-accommodators) \\
\hline Initial refraction-prescription difference (D) (fe) & $1.60 \pm 0.41$ (range: $0.75-2.50)$ & $1.62 \pm 0.51$ (range: $0.75-2.50)$ \\
\hline Initial refraction-prescription difference (D) (nfe) & $1.62 \pm 0.48($ range: $0.25-2.25)$ & $1.72 \pm 0.87$ (range: $0.50-4.50)$ \\
\hline Final refraction-prescription difference (D) (fe) & $1.34 \pm 0.65^{*}$ (range: $0.25-2.25$ ) & $1.17 \pm 0.41^{* * * *}$ (range: $0-2.0$ ) \\
\hline Final refraction-prescription difference (D) (nfe) & $1.24 \pm 0.67$ (range: $0.50-2.50$ ) & $1.08 \pm 0.44^{* *}$ (range: $\left.0-2.0\right)$ \\
\hline
\end{tabular}

Abbreviations: D, diopters; DR, dynamic retinoscopy; fe; fixating eye; nfe; non-fixating eye.

$* P=0.04$.

**DR response over final prescription: least hyperopic correction to result in $\mathrm{N} / \mathrm{N}$ responses with DR. 
Even in the absence of significant refractive anisometropia at the beginning of the study, DR-based prescribing might contain a risk of inducing gradual increases in the amount of anisometropia in spectacles and a 'later anisometropia' (which is then in the form of 'spectacle anisometropia') could be created during the course of the study. In our study, later anisometropia, ${ }^{30-34}$ which was still under $<1.0 \mathrm{D}$, did not contribute to the development of strabismus. It is possible that DR-based glasses allowing full accommodation of the non-fixing eyes negated the effects of insufficient accommodation on vision deprivation. Also, DR trends in our findings for fixating s eyes were similar to those of their non-fixating fellows, which prevented significant increases in the initial anisometropia.

Table 2c Accommodative response changes before and after strabismus among Group 2B

\begin{tabular}{cc}
\hline Initial refraction-initial & Last refraction-least \\
prescription & hyperopic correction to \\
& result in N/N responses \\
& with $D R$
\end{tabular}

Fixing eye $\quad 1.62 \pm 0.51 *$ (range: $0.75-2.5) \quad 1.17 \pm 0.41^{*}$ (range: $0-2.0$ ) Non-fixing eye $1.72 \pm 0.87^{* *}$ (range: $\left.0.50-4.50\right) \quad 1.08 \pm 0.44^{* *}$ (range:0-2.0)

Abbreviation: DR, dynamic retinoscopy.

${ }^{*} P=0.002$.

${ }^{* *} P<0.001$

Table 3 Anisometropic change due to prescriptions given in accordance with DR

\begin{tabular}{lll}
\hline & $\begin{array}{c}\text { Ortho hypo- } \\
\text { accommodators } \\
\text { (Group 2A) }\end{array}$ & $\begin{array}{c}\text { Esotropic hypo- } \\
\text { accommodators } \\
\text { (Group 2B) }\end{array}$ \\
\hline Initial refractive anisometropia (D) & $0.69 \pm 0.38$ & $0.70 \pm 0.31$ \\
Initial spectacle anisometropia (D) & $0.61 \pm 0.44$ & $0.54 \pm 0.43$ \\
Late refractive anisometropia $^{a}$ (D) & $0.60 \pm 0.51^{*}$ & $0.83 \pm 0.57^{* *}$ \\
Late spectacle anisometropia $^{\text {(G) }}$ (D) & $0.60 \pm 0.51^{*}$ & $0.86 \pm 0.53^{* *}$
\end{tabular}

Abbreviations: D, diopters; DR, dynamic retinoscopy.

${ }^{*} P=0.97$.

${ }^{* *} P=0.73$.

a Among Group 2B, refers to refractive and spectacle anisometropia at time of detection of strabismus.
All initial normal accommodators and all hypoaccommodators without strabismus development had 0.63-1.0 decimal (0.2-0.0 LogMAR) visual acuities at 3-4 years, which were normal values for this age interval. ${ }^{35-37}$ It would be interesting to know whether following normal accommodators (Group 1) without prescriptions, which helped them use their accommodative reserve efficiently, did any good in achieving good visual acuities. All children who developed strabismus had lower visual acuities at 3-4 years. Ingram et al 23,24 referred to the defective acuity among nonhyperopic strabismic eyes and pointed out that low vision among these could be caused by an underlying amblyopia similar to that in untreated high hyperopic strabismics, on which the effects of vision deprivation also had been superimposed. Group 2 consists of higher hyperopes than Group 1, but with full-time-use spectacles, we do not have evidence that these strabismic children suffered from vision deprivation caused by the amount of hyperopia. It is likely that, if full refractive corrections were prescribed initially, these infants would still have low vision.

Among the fixating eyes of the 146 patients with N/N initial DR responses followed without glasses (Group 1), hyperopic decline was $0.37 \pm 0.25 \mathrm{D}$ per year $(1.12 \pm 0.8 \mathrm{D}$ through mean $35.4 \pm 2.1$ months), comparable with some of the limited data in previous studies, in which Atkinson et $\mathrm{al}^{1}$ reported a 1.2 D decline through 9-36 months ( $0.6 \mathrm{D}$ per year) from an initial hyperopia $>3.5 \mathrm{D}$ in one or more meridian. Ingram et $a l^{24,25}$ reported a 0.54-1.24 D decline through 6-42 months of age in two different studies from an initial more than 5.25D hyperopia in at least one meridian Saunders et al ${ }^{38}$ reported a $0.06 \mathrm{D}$ decline per month for each diopter of hyperopia during 12-17 months of age from an initial mean of $1.25-4.25 \mathrm{D}$.

Among the 65 patients in Group 2, there were greater overall changes in hyperopia compared with those in Group 1. Group 2 consisted of higher hyperopic infants than Group 1. Consistent with the results of the previous studies, 5,38 the reduction in hyperopia was

Table 4a Distribution of spherical refractive measurements among groups

\begin{tabular}{|c|c|c|c|}
\hline & $\begin{array}{c}\text { Group } 1 \\
\text { (normal accommodators) }(\mathrm{n}=146)\end{array}$ & $\begin{array}{c}\text { Group 2A } \\
\text { (ortho hypo-accommodators) }(\mathrm{n}=34)\end{array}$ & $\begin{array}{c}\text { Group } 2 B \\
\text { (esotropic hypo-accommodators) }(\mathrm{n}=31)\end{array}$ \\
\hline Initial refraction $(\mathrm{fe})$ & $3.9 \pm 0.8^{*}($ range: $3.0-7.0)$ & $4.9 \pm 1.0^{*}$ (range: $3.25-7.0$ ) & $7.6 \pm 1.5^{*}$ (range: $5.5-11.0$ ) \\
\hline Initial refraction (nfe) & $4.3 \pm 0.7^{*}$ (range: $\left.3.0-7.0\right)$ & $5.4 \pm 1.0^{*}$ (range: $\left.3.5-7.0\right)$ & $8.2 \pm 1.6^{*}$ (range: $5.75-12.0$ ) \\
\hline Last refraction $(\mathrm{fe})$ & $2.8 \pm 0.8^{* *, * * *}$ (range: $0.5-4.5$ ) & $3.4 \pm 0.7^{* *}$ (range: $2.0-4.5$ ) & $5.8 \pm 1.9^{* * *}$ (range: $3.5-10.0$ ) \\
\hline Last refraction (nfe) & $3.1 \pm 0.8^{*}($ range: $1.0-4.75)$ & $3.8 \pm 0.7^{*}$ (range: $\left.2.75-5.5\right)$ & $6.5 \pm 1.7^{*}($ range: $4.0-10.5)$ \\
\hline
\end{tabular}

Abbreviations: fe; fixating eye; $n$, number of cases; nfe; non-fixating eye.

${ }^{*} P \leq 0.001$ among Group 1, Group 2A, and Group 2B.

${ }^{* *} P=0.005$ among Group 1 and Group 2A.

${ }^{* * *} P<0.001$ among Group 1 and Group 2B. 
Table $4 \mathrm{~b}$ Mean spherical refractive change among groups

\begin{tabular}{lccc}
\hline $\begin{array}{l}\text { Spherical refractive change } \\
\text { (normal accommodators) }(\mathrm{n}=146)\end{array}$ & \multicolumn{1}{c}{$\begin{array}{c}\text { Group 2A } \\
\text { (ortho hypo-accommodators }(\mathrm{n}=34)\end{array}$} \\
\hline Fixing eye & $-1.12 \pm 0.77^{*}($ range: $0-(-4.0))$ & $-1.50 \pm 0.83$ (range: $(-0.25)-(-3.25))$ & $-1.81 \pm 0.59^{*}($ range: $(-0.75)-(-2.5))$ \\
Non-fixing eye & $-1.19 \pm 0.80^{* * * * *}($ range: $0-(-3.5))$ & $-1.56 \pm 0.83^{* *}($ range: $(0.25)-(-3.5))$ & $-1.73 \pm 0.78^{* * *}($ range: $0-(-4.5))$ \\
\hline
\end{tabular}

Abbreviation: $\mathrm{n}$, number of cases.

${ }^{*} P \leq 0.001$.

${ }^{* *} P=0.046$.

$* * * P=0.002$.

greater when the initial hyperopic error was greater. There appears to have been no significant difference in emmetropization between Groups 2A and 2B.

Hyperopic decline was $1.50 \pm 0.8 \mathrm{D}$ through the mean $35.4 \pm 2.1$ months and $1.80 \pm 0.6 \mathrm{D}$ through the mean $35.4 \pm 2.1$ months among Groups $2 \mathrm{~A}$ and $2 \mathrm{~B}$, respectively, which were higher emmetropization rates compared with previous studies. In the study of Atkinson et al, ${ }^{12}$ they found a reduction of $1.2 \mathrm{D}$ (similar to their untreated group, which consisted of children followed without glasses) through 9-36 months with partial-spectacle corrections. Ingram's group ${ }^{7}$ found a reduction of $0.42 \mathrm{D}$ among non-strabismic cases and a $0.89 \mathrm{D}$ decline among strabismic cases through 6-42 months of age. In the abovementioned studies, similar to the untreated groups, the treated groups consisted of a random sample of infants who met the criteria for the refractive error categories. Some form of assessment of accommodative ability, which is not always a function of the level of hyperopia, was not utilized as part of selection criteria. The rate at which emmetropization occurred seemed to be mostly related to the initial level of hyperopia present. Although the data are inadequate to clarify the validity of our claim, we attribute the higher emmetropization rates in our treated groups to the maintenance of full accommodative ability, which we feel may have helped the process of emmetropization.

The similar emmetropization rates among Groups 2A and $2 \mathrm{~B}$ might raise questions regarding why the addition of extra plus in spectacles did not cause any delays is emmetropization among Group 2B. The reason seems to be the accomplishment of plus lenses only after the detection of strabismus, which was at a mean age of $29.3 \pm 7.3$ (range 18-42 months), after the period during which the majority of refractive change was already completed. The emmetropization rate therefore was not influenced.

Another observation on this sample of children was that, if DR revealed an initial $\mathrm{N} / \mathrm{N}$ response, refractive error was between +3.0 and $+7.0 \mathrm{D}$. This is a wide range with potentially amblyopic refractive errors and high risk of strabismus, suggesting that this test, used alone, is not a suitable screening tool for high hyperopia. Even if binocular accommodative response is normal at first visit, DR has to be followed by cycloplegic refraction. We also want to emphasize that, in this study, if DR revealed an $\mathrm{H} / \mathrm{H}$ response, the hyperopic refractive error after cycloplegia was always $\geq+3.25 \mathrm{D}$.

This study needs to be viewed in light of the following limitations. Probably the biggest limitation is that we excluded patients whose anisometropia exceeded $+1.25 \mathrm{D}$. One cannot extrapolate results from this study with confidence to patients who have higher amounts of anisometropia. Also, we evaluated a group of infants with $\geq 5 \mathrm{D}$ of hyperopia; whether our observations are applicable to all patients with $\geq 5 \mathrm{D}$ of hyperopia may be subject to question.

Another limitation is the low number of subjects examined; however, given the incidence of hyperopia $\geq 5 \mathrm{D}^{1,3}$ review of a larger series would be difficult. There were no comparison groups demonstrating no correction, full correction, or different forms of partial correction. We are also aware that DR is a subjective test with the potential for inter-observer variability, but we have been performing it for infants and children as a part of routine office examination for many years and believe that the data were sufficiently accurate for the purposes of this study.

Based on the data reported herein, the following conclusions have been identified:

1. Hyperopic orthotropic infants with normal accommodation with DR do not develop esotropia, even if the lenses are not prescribed and they have normal visual acuities after the emmetropization period.

2. Accommodative lag at 3-12 months may be an indicator of future strabismus and poor visual outcome. Only infants with initial $\mathrm{H} / \mathrm{H}$ responses at the initial visit are candidates for strabismus.

3. Prescription of hyperopic correction to hyperopic orthotropic infants according to the least amount needed to allow for near focusing, based on DR, does not impede emmetropization and result in normal visual acuities after the emmetropization period. 


\section{Summary}

\section{What was known before}

- Early prescription of glasses has been suggested as a way of setting preventive measures for the development of strabismus and amblyopia among orthotropic hyperopic children.

- However, it also introduces the tendency to place undue weight in the face of deferring the development of emmetropization.

- This concern raises a question that is yet to be answered: do hyperopic children really need the provision of full plus refractive error correction to meet these objectives?

\section{What this study adds}

- DR can perhaps guide decision.

- Accommodative lag with DR at 3-12 months may be an indicator of future strabismus and poor visual outcome.

- Only infants with accommodative lag at the initial visit are candidates for strabismus.

- Hyperopic orthotropic infants with normal accommodation do not develop esotropia, even if the lenses are not prescribed and have normal visual acuities after the emmetropization period.

- Prescription of hyperopic correction to hyperopic orthotropic infants according to the least amount needed to allow for near focusing, based on DR, does not impede emmetropization and result in normal visual acuities after the emmetropization period.

\section{Conflict of interest}

The authors declare no conflict of interest.

\section{Author contributions}

DS: conception and design, acquisition of data, analysis and interpretation, literature search, drafting the article, and final approval of the version published; EK: acquisition of data, analysis and interpretation, literature search, drafting the article, and statistical expertise; FC: acquisition of data, provision of materials, patients, or resources; UEA: statistical expertise; NU: administrative, technical, or logical support.

\section{References}

1 Atkinson J, Braddick O, Nardini M, Anker S. Infant hyperopia: detection, distribution, changes and correlatesoutcomes from the cambridge infant screening programs. Optom Vis Sci 2007; 84(2): 84-96.

2 Mutti DO. To emmetropize or not to emmetropize? The question for hyperopic development. Optom Vis Sci 2007; 84(2): 97-102.

3 Ingram RM, Arnold PE, Dally S, Lucas J. Results of a randomized trial of treating abnormal hypermetropia from the age of 6 months. Br J Ophthalmol 1990; 74(3): 158-159.

4 Atkinson J, Braddick O, Robier B, Anker S, Ehrlich D, King J et al. Two infant vision screening programmes: prediction and prevention of strabismus and amblyopia from photo- and videorefractive screening. Eye (Lond) 1996; 10(Pt 2): 189-198.

5 Li C, Chen PL, Chen JT, Fu JJ. Different corrections of hypermetropic errors in the successful treatment of hypermetropic amblyopia in children 3 to 7 Years of age. Am J Ophthalmol 2009; 147(2): 357-363.

6 Wildsoet CF. Active emmetropization-evidence for its existence and ramifications for clinical practice. Ophthalmic Physiol Opt 1997; 17(4): 279-290.

7 Troilo D, Wallman J. The regulation of eye growth and refractive state: an experimental study of emmetropization. Vision Res 1991; 31(7-8): 1237-1250.

8 Schaffel F, Troilo D, Wallmann J, Howland HC. Developing eyes that lack accommodation grow to compansate for imposed defocus. Vis Neurosci 1990; 4(2): 177-183.

9 Winaver J, Zhu X, Choi J, Wallman J. Ocular compensation for alternating myopic and hyperopic defocus. Vision Res 2005; 45(13): 1667-1677.

10 Zhu X, Winawer JA, Wallman J. Potency of myopic defocus in spectacle lens compensation. Invest Ophthalmol Vis Sci 2003; 44(7): 2818-2827.

11 Candy TR, Wang J, Ravikumar S. Retinal image quality and postnatal visual experience during infancy. Optom Vis Sci 2009; 86(6): E556-E571.

12 Atkinson J, Anker S, Bobier W, Braddick O, Durden K, Nardini $\mathrm{M}$ et al. Normal emmetropization in infants with spectacle correction for hyperopia. Invest Ophthalmol Vis Sci 2000; 41(12): 3726-3731.

13 Cook RC, Glascock RE. Refractive and ocular findings in the newborn. Am J Ophthalmol 1951; 34(10): 1407-1413.

14 Jones LA, Mitchell GL, Mutti DO, Hayes JR, Moeschberger ML, Zadnik K. Comparison of ocular component growth curves among refractive error groups in children. Invest Ophthalmol Vis Sci 2005; 46(7): 2317-2327.

15 Wood IC, Hodi S, Morgan L. Longitudinal change of refractive error in infants during the first year of life. Eye 1995; 9(Pt 5): 551-557.

16 Mayer DL, Hansen RM, Moore BD, Kim S, Fulton AB. Cycloplegic refractions in healthy children aged 1 through 48 months. Arch Ophthalmol 2001; 119(11): 1625-1628.

17 Saladin JJ. Phorometry and stereopsis. In: Benjamin WJ. ed. Borish's Clinical Refraction. Butterworth Heineman Co (Elsevier): St Louis, MO, USA, 2006; 914-915.

18 Hunter DG. Dynamic retinoscopy: the missing data. Surv Ophthalmol 2001; 46(3): 266-274.

19 Guyton DL, O'Connor GM. Dynamic retinoscopy. Curr Opin Ophthalmol 1991; 2(1): 78-80.

20 Eskridge JB. Clinical objective assessment of the accommodative response. J Am Optom Assoc 1989; 60(4): 272-275.

21 Somer D, Cinar FG, Duman S. The accommodative element in accommodative esotropia. Am J Ophthalmol 2006; 141(5): 819-826.

22 Mutti DO, Mitchell GL, Jones LA, Friedman NE, Frane SL, Lin WK et al. Accommodation, acuity and their relationship to emmetropization in infants. Optom Vis Sci 2009; 86(6): 666-676.

23 Ingram RM, Arnold PE, Dally S, Lucas J. Emmetropisation, squint, and reduced visual acuity after treatment. $\mathrm{Br} J$ Ophthalmol 1991; 75(7): 414-416.

24 Ingram RM, Gill LE, Lambert TW. Effect of spectacles on changes of spherical hypermetropia in infants who did, and did not, have strabismus. Br J Ophthalmol 2000; 84(3): 324-326. 
25 Ingram RM, Lambert TW, Gill LE. Visual outcome of 879 children treated for strabismus: insufficient accommodation and vision deprivation, deficient emmetropization and anisometropia. Strabismus 2009; 17(4): 148-157.

26 Owens DA, Mohindra I, Held R. The effectiveness of a retinoscope beam as an accommodative stimulus. Invest Ophthalmol Vis Sci 1980; 19(8): 942-949.

27 Diamond GR. Evaluating vision in preverbal and preliterate infants and children. In: Yanoff M, Duker JS (eds). Ophthalmology 3rd edn. Mosby (Elsevier Health Sciences): St Louis, MO, USA, 2009, pp 1309-1312.

28 Becker R, Hübsch S, Graf MH, Kaufmann H. Examination of young children with Lea symbols. Br J Ophthalmol 2002; 86(5): 513-516.

29 Robbins SL, Christian WK, Hertle RW, Granet DB. Vision testing in the pediatric population. Ophthalmol Clin North Am 2003; 16(2): 253-267.

30 Birch EE, Fawcett SL, Morale SE, Weakley Jr DR, Wheaton DH. Risk factors for accommodative esotropia among hypermetropic children. Invest Ophthalmol Vis Sci 2005; 46(2): 526-529.

31 Colburn JD, Morrison DG, Estes RL, Li C, Lu P, Donahue SP. Longitudinal follow-up of hypermetropic children identified during preschool vision screening. I AAPOS 2010; 14(3): 211-215.

32 Ingram RM, Gill LE, Lambert TW. Emmetropization in normal and strabismic children and the associated changes of anisometropia. Strabismus 2003; 11(2): 71-84.

33 Weakley DR, Birch EE. The role of anisometropia in the development of accommodative esotropia. Trans Am Ophthalmol Soc 2000; 98: 71-76.

34 Weakley Jr DR. The association between nonstrabismic anisometropia, amblyopia, and subnormal binocularity. Ophthalmology 2001; 108(1): 163-171.

35 Simons K. Visual acuity norms in young children. Surv Ophthalmol 1983; 28(2): 84-92.

36 Mayer DL, Beiser AS, Warner AF, Pratt EM, Raye KN, Lang JM. Monocular acuity norms for the Teller acuity cards between ages one month and four years. Invest Ophthalmol Vis Sci 1995; 36(3): 671-685.

37 Pan Y, Tarczy-Hornoch K, Cotter SA, Wen G, Borchert MS, Azen SP et al. Visual acuity norms in pre-school children: the Multi-Ethnic Pediatric Eye Disease Study. Optom Vis Sci 2009; 86(6): 607-612.

38 Saunders KJ, Woodhouse JM, Westall CA. Emmetropisation in human infancy: rate of change is related to initial refractive error. Vision Res 1995; 35(9): 1325-1328. 